\title{
Use of Fetotomy Technique to Resolve Dystocia due to Wry Neck Ankylosed Fetus in a Mare
}

\author{
Navdeep Singh ${ }^{1 *}$, Sarvpreet SinghGhuman ${ }^{2}$, Navgeet Singh $^{3}$, \\ Navjot Singh $^{3}$ and Randhir Singh ${ }^{3}$
}

${ }^{1}$ Veterinary Gynaecologist, Directorate of Livestock Farm, ${ }^{2}$ Department of Teaching Veterinary Clinical Complex, ${ }^{3}$ Department of Veterinary Gynaecology and Obstetrics, Guru Angad Dev Veterinary and Animal Sciences University, Ludhiana - 141 004, India

*Corresponding author

\section{A B S T R A C T}

Keywords

Ankylosis,

Dystocia, Fetotomy,

Wry neck, Mare

Article Info

Accepted:

17 March 2019

Available Online:

10 April 2019

\section{Introduction}

Period of foaling is considered as a critical event for equine breeders. Any abnormality during foaling is one of the most challenging conditions faced by equine practitioners. The incidence of dystocia is reported to be $4 \%$ in thoroughbred mares and malposture of long fetal extremities, head, and neck are the major cause of dystocia in mare (Thangamani et al., 2018). Furthermore, the time taken during obstetrical maneuvering is very crucial for the survivability of fetus and mare as well as the subsequent fertility of the mare (Frazer, 2007). One or two well-placed fetotomy cuts can dramatically shorten the intervention time (Nimmo et al., 2007). The present report describes a rare case of dystocia in a mare due to wry neck ankylosed fetus and its successful management through partial fetotomy operation.

\section{Case history and observations}

A six years old full-term pregnant mare in her second parity was presented to the University Veterinary Hospital with the history of severe straining for the last 6-8 hours. Visibly, both ankylosed forelimbs with knee flexion were hanging out from the vulva (Fig. 1). General 
clinical examination revealed that the mare was alert with $102.4^{\circ} \mathrm{F}$ body temperature. Mare's tail was wrapped and the perineal region was thoroughly cleansed with an antiseptic solution.

Following epidural anesthesia with $5 \mathrm{ml}$ of $2 \%$ Lignocaine hydrochloride solution at first inter-coccygeal space, a thorough vaginal examination was performed which revealed a fully dilated cervix with moist birth canal. The fetus, without any reflex, was in anterior longitudinal presentation with severe lateral deviation of the head. The neck seemed to be stiff (wry neck). Taking all these findings into consideration, it was decided to relieve dystocia through fetotomy.

\section{Treatment}

Following epidural anesthesia and ample lubrication with $1 \%$ solution of sodium salt of carboxymethyl cellulose gel, partially loaded fetotome was introduced in the uterus and wire was placed around neck with the help of calving rope carrier. Head of the fetotome was placed at the base of the neck between both forelimbs (Fig. 2). After amputating the fetal head at the level of the neck, it was removed by applying traction. The head amputation proved miraculous which resulted in the delivery of rest of the fetus by applying traction on forelimbs after lubrication. The mare was discharged with the routine prescription of antibiotics and supportive therapy and referred to the general veterinarian for medical follow-up.

Fig.1 Mare at case presentation; both ankylosed forelimbs hanging out from vulva




Figure.2 Foal with wry neck and ankylosed limbs; placement of fetotome

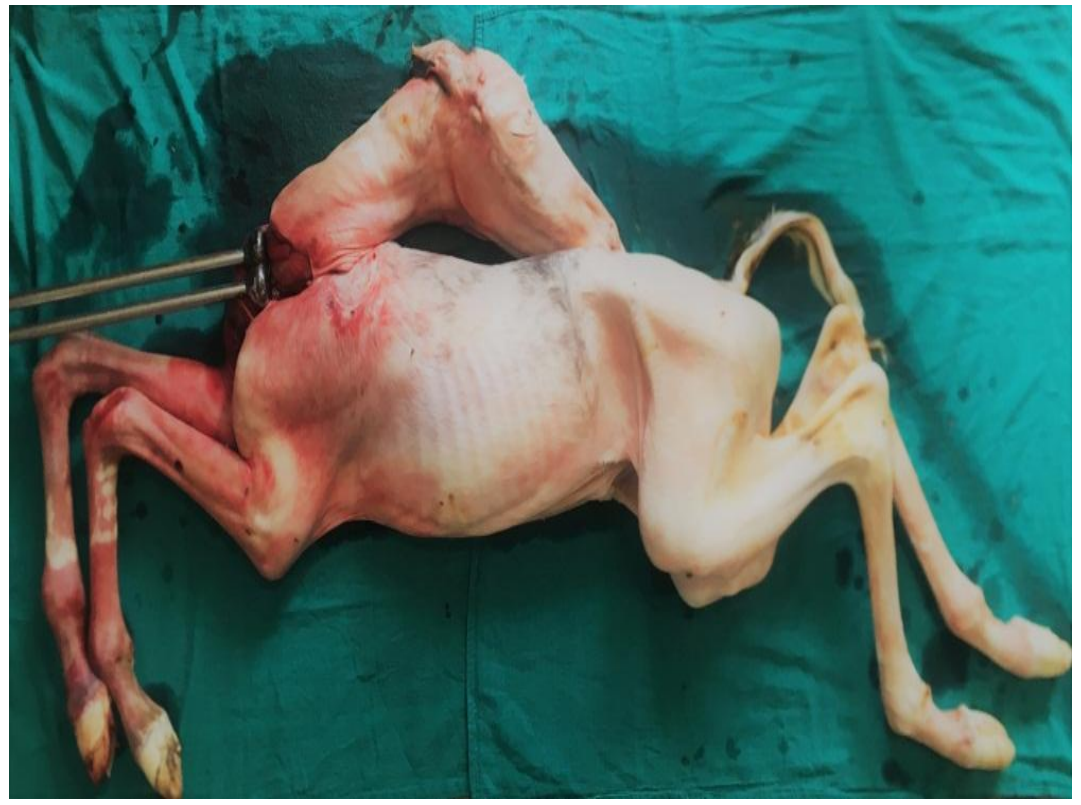

The incidence of dystocia in mare has been much less documented than bovines (Frazer, 2007). Fetal monsters are rare in horses. However, hydrocephalus (Dugdale, 2007), Schistosomar eflexus, ankylosis of one or more limbs and wry neck are known to occur (Ball 2005). Maldisposed dead fetuses can be safely resolved for vaginal delivery through fetotomy performed by skilled persons, otherwise, it is potentially hazardous for the mare (Higgins and Wright, 1999). One to two well-placed fetotomy cuts can dramatically shorten the intervention time and permit a traumatic delivery of a nonviable fetus (Nimmo et al., 2007). The value of mare is an important factor to be considered. In one study, one or two cuts were sufficient to correct $57 \%$ of the cases, and another $21 \%$ required a third cut (Frazer, 1997). The survival rate of mares subsequent to fetotomy was $95.8 \%$ in one study (Carluccio et al., 2007) and 100 percent in another (Volkmann, 2009). The short term and long term fertility of mares appears to be good with 80 to $83 \%$ mares conceiving subsequently (Carluccio et al., 2007; Nimmo et al., 2007).

\section{Summary}

In the present case, dystocia in a mare due to fetal abnormalities viz. ankylosis of forelimbs and wry neck was observed. A single cut on the neck to amputate and remove head proved helpful in the delivery of malpostured fetus. It is thus concluded that fetotomyis a potential tool to relieve dystocia due to wry neck and ankylosed fetal limbs in mares. Furthermore, fetotomy is a relatively non-invasive and economical way to handle these obstetrical emergencies when compared to the cesarean section. Also, recovery is uneventful without much intensive care and complications which may otherwise be encountered after the cesarean section.

\section{References}

Ball, B.A. 2005. Dystocia in the mare: Management and decision making. Proc. Annu. Meet Italian Assoc. Equine Vet pisa. p1-4 Italy.

Carluccio, A., Contri, A., Tosi, U., De Amicis, I., De Fantic. 2007. Survival rate and short term fertility rate 
associated with the use of fetotomy for resolution of dystocia in mare: 72 cases (1991-2005). J. Am. Vet. Med. Assoc. 230: 1502-1505.

Dugdale, D.J. 2007. Dystocia- BEWA Equine Stud Medicine Course p 225-28.

Frazer, G.S.2007. Dystocia and Fetotomy. In: Samper JC, Pycock JF, Mc Kinnon AO eds Current Therapy in Equine Reproduction. Saunders Elsevier. Missourri. Pp. 417-34.

Frazer, G.S., Perkins, N.R., Blanchard, T.L., Lock, T.F., Sertich, P.L., Baker, G.J., Vaala, W.E. 1997. Prevalence of fetal maldispositions in equine referral hospital dystocias. Equine. Vet. J. 29: 111-116

Higgins, A.J., Wright, I.M. 1999. The Equine
Manual, Saunders, Oval Road, London. Nimmo, M.R., Slone, D.E., Hughes, F.E., Linch, T.M, Clark, C.K. 2007. Fertility and Complications after fetotomy in twenty brood mares (2001-2006). Vet. Surg. 36: 771-774.

Stephenson, R. 2010. Correction of dystocia in a mare by fetotomy. UK. Vet. 15: 913.

Thangamani, A., Srinivas, M., Chandraprasad, B., and Phanikumar, L. 2018. Periparturient event and dystocia in equine- A review. Int. J. Sci. Environ. Tech. 7(2): 648-658.

Volkmann, D. 2009. Practical management of equine dystocia. Proc. Scientific. Assoc. for health (WVGP) Merelbeke. Pp. 111.

\section{How to cite this article:}

Navdeep Singh, Sarvpreet Singh Ghuman, Navgeet Singh, Navjot Singh and Randhir Singh. 2019. Use of Fetotomy Technique to Resolve Dystocia due to Wry Neck Ankylosed Fetus in a Mare. Int.J.Curr.Microbiol.App.Sci. 8(04): 2464-2467. doi: https://doi.org/10.20546/ijcmas.2019.804.287 